\title{
Association of Bovine Fibroblast Growth Factor 2 (FGF2) Gene with Milk Fat and Productive Life: An Example of the Ability of the Candidate Pathway Strategy to Identify Quantitative Trait Genes
}

\author{
X. Wang, ${ }^{*} \dagger$ C. Maltecca, ${ }^{*}$ R. Tal-Stein, $\ddagger$ E. Lipkin, $\neq$ and H. Khatib ${ }^{* 1}$ \\ *Department of Dairy Science, University of Wisconsin-Madison, Madison 53706 \\ †College of Animal Science and Technology, Northwest A\&F University, Yangling, Shaanxi, 712100, China \\ $\ddagger$ \epartment of Genetics, Alexander Silberman Institute of Life Science, Hebrew University of Jerusalem, Jerusalem 91904, Israel
}

\begin{abstract}
Fibroblast growth factor 2 (FGF2) is expressed in the bovine mammary gland and may play a role in the development and reorganization of the mammary gland. It is also expressed by the uterine endometrium throughout the estrous cycle and early pregnancy. The FGF2 was chosen for this study because it regulates the expression of interferon- $\tau$, a key member of the signal transduction pathway involved in milk production. In previous studies, we reported the association of several genes in this pathway with milk production and health traits in dairy cattle. The objective of this study was to examine the association of FGF2 polymorphisms with milk composition, somatic cell score, and productive life in 3 Holstein cattle populations from the United States and Israel. The pooled DNA sequencing approach was used to identify single nucleotide polymorphisms (SNP) in FGF2. Sequencing of a total of 6.4 $\mathrm{kb}$ including 3 exons of the gene revealed only one SNP $(\mathrm{A} / \mathrm{G})$ in intron 1 at position 11646 . This SNP was investigated for association with production traits in 2,773 individuals from 3 Holstein populations: the granddaughter-design Cooperative Dairy DNA Repository and the daughter-design University of Wisconsin populations from the United States and a daughter-design population from Israel. For both the Israeli and the UW populations, FGF2 variants were associated with fat yield and percentage, somatic cell score, and productive life with significant dominance and complete dominance effects. For the Cooperative Dairy DNA Repository population, no significant associations were observed for the examined traits. Given that FGF2 was chosen for this study because of its role in the interferon- $\tau$ signal transduction pathway and was found to be associated with production traits, results suggest
\end{abstract}

Received November 19, 2007.

Accepted February 18, 2008

${ }^{1}$ Corresponding author: hkhatib@wisc.edu that the candidate pathway could be an attractive strategy to search for candidate quantitative trait genes.

Key words: $F G F 2$ gene, milk composition, productive life, candidate pathway

\section{INTRODUCTION}

At present, the major challenge of genomic and genetic studies in livestock species is the identification and mapping of individual QTL and quantitative trait genes that control agricultural traits. Candidate genes are typically chosen based on the results of previous linkage mapping studies and on comparative biological or physiological functions in other species (Rothschild and Soller, 1997). A review of recent publications shows that many QTL have been mapped for traits of economic importance in dairy cattle (Khatkar et al., 2004; www.animalgenome.org). However, despite the large number of QTL studies in cattle and other species, little progress has been made on the identification of major genes affecting milk production and health traits in dairy cattle. One major limitation when choosing a candidate gene is the large number of provisional genes present in most QTL regions.

Previous studies from this research group have shown that several genes of the interferon- $\tau$ (IFNT) and placental lactogen signal transduction pathway were associated with milk production, health, and fertility traits in dairy cattle (Leonard et al., 2005; Cobanoglu et al., 2006; Khatib et al., 2007a, 2008). In this pathway, bovine IFNT is released by the conceptus as early as d 9 of pregnancy and serves as the signal for maternal recognition of pregnancy. Interferon- $\tau$ binds to the receptor IFNAR, which is present on the cells of the endometrium and activates a cascade of protein phosphorylation events including activation of signal transducer and activator of transcription (STAT) 1 and STAT2, which in turn lead to the secretion of uterine milk protein (UTMP) and osteopontin (OPN) proteins (Spencer and Bazer, 2002; Stewart et al., 2002). We showed that OPN, STAT1, and UTMP have significant associations 
with milk composition and health traits in dairy cattle (Leonard et al., 2005; Cobanoglu et al., 2006; Khatib et al., 2007a,b). Furthermore, we showed that STAT5A (a member of the signal transduction pathway of IFNT and placental lactogen) is associated with milk composition, early embryonic survival, and fertilization success (Khatib et al., 2008).

Fibroblast growth factor 2 (FGF2), located on distal chromosome 6 , is expressed by the bovine endometrium throughout the estrous cycle and early pregnancy and regulates trophectoderm expression of IFNT, the maternal recognition factor of pregnancy in ruminants (Michael et al., 2006; Ocón-Grove et al., 2008). Plath et al. (1998) reported the expression of FGF2 in the bovine mammary gland during the different developmental stages and suggested, based on the concentrations of mRNA and protein, that FGF2 might be important for the development and reorganization of the mammary gland. Taken together, the objective of this study was to examine the association of FGF2 polymorphisms with milk production traits and productive life in 3 different Holstein populations.

\section{MATERIALS AND METHODS}

\section{Populations and Phenotypic Data}

The association between $F G F 2$ and milk production and health traits was examined in a total of 2,773 individuals from 3 different Holstein cattle populations: the University of Wisconsin (UW) resource population, the Cooperative Dairy DNA Repository (CDDR) population, and the Israeli Holstein population. For a detailed description of the UW populations, see Gonda et al. (2006) and Khatib et al. (2007a). Yield deviation (YD) and PTA data for the UW population and PTA data for the CDDR population for milk yield, milk protein and fat yields and percentages, productive life (PL), and SCS were obtained from the Animal Improvement Programs Laboratory (Beltsville, MD). The phenotypic data for the Israeli Holstein population comprised EBV for milk yield, milk fat and protein yields and percentages, and SCS. A summary statistics of phenotypic data from the 3 resource populations is given in Table 1 .

\section{DNA Preparation, Polymorphism Detection, and Genotyping}

A total of 851 blood samples were obtained from the UW resource population. Genomic DNA was extracted by using GFX Genomic Blood DNA Purification kit (Amersham Biosciences, Piscataway, NJ). Semen samples from the CDDR population were obtained from 27 sires and their 1,316 sons, and genomic DNA was extracted by standard methods using proteinase $\mathrm{K}$ and phenol/ chloroform. For the Israeli population, milk samples were obtained from 606 milk-recorded Israeli-Holstein dairy cows. Somatic cell counts of the milk samples were obtained from the central milk-testing laboratory of the Israel Cattle Breeders Association. Genomic DNA was extracted from milk samples by using GFX Genomic Blood DNA Purification kit (Amersham Biosciences).

To detect single nucleotide polymorphisms (SNP) in the FGF2 gene (GenBank accession number NC_007304), 14 different sets of primers were designed (Table 2) to amplify a total of 6,389 bp (including all exons of the gene) using pooled DNA samples of 30 individuals. The PCR products were sequenced and SNP were identified by visually inspecting sequence traces.

For individual genotyping, the primers FGF2-F 5' CATAGTTCTGTAGACTAGAAG $3^{\prime}$ and FGF2-R 5' CC TCTAAAGAAGGATTAAGTCAAAATGGGGCTGGTA $3^{\prime}$ were used to amplify a 207-bp fragment. The sequence of primer FGF2-R was modified to include a recognition site for the restriction enzyme Csp6I. Amplification was performed in a $25-\mu \mathrm{L}$ reaction volume, which included $50 \mathrm{ng}$ of genomic DNA, $50 \mathrm{ng}$ of each primer, $200 \mu M$ each dNTP, $2.5 \mu \mathrm{L}$ of $10 \times$ PCR buffer (Promega, Madison, WI), and 0.5 units of Taq DNA polymerase (Promega). The temperature cycles were as follows: $95^{\circ} \mathrm{C}$ for $5 \mathrm{~min}$, followed by 32 cycles of $94^{\circ} \mathrm{C}$ for $45 \mathrm{~s}$, touchdown annealing from 63 to $50^{\circ} \mathrm{C}$ for 45 $\mathrm{s}\left(-2^{\circ} \mathrm{C} /\right.$ cycle $), 72^{\circ} \mathrm{C}$ for $45 \mathrm{~s}$, and a final extension at $72^{\circ} \mathrm{C}$ for $8 \mathrm{~min}$. The PCR products were digested with the restriction enzyme $C s p 6 \mathrm{I}$ and electrophoresed on a $2.0 \%$ agarose gel. The A allele was indicated by a band of $207 \mathrm{bp}$, and the $\mathrm{G}$ allele was indicated by a band of $171 \mathrm{bp}$.

\section{Statistical Analysis}

Association of FGF2 variants with milk production and health traits was evaluated in 3 Holstein cattle populations. For the granddaughter-design CDDR population, PTA for each trait were analyzed using the following allele substitution effect model:

$$
y_{i j}=\mu+s_{i}+\beta x_{i j}+\varepsilon_{\mathrm{ij}}
$$

where $y_{i j}$ represents the PTA of bull $j$ of sire $i ; \mu$ is a general constant; $s_{i}$ is the fixed effect of sire $i ; \beta$ is the regression coefficient representing half the allele substitution effect $(\alpha / 2) ; x_{i j}$ represents the number of allele $\mathrm{G}$ copies $(0,1,2)$ at the $F G F 2$ locus of bull $j$ of sire $i$; and $\varepsilon_{i j}$ represents the random residual term.

For the daughter-design UW population, dominance effects for individual cow PTA and YD for each trait were analyzed using the following mixed model: 
Table 1. Means and SD of PTA of cows in the University of Wisconsin (UW), of sons in Cooperative Dairy DNA Repository (CDDR), and of EBV of cows in the Israeli resource populations for the production traits

\begin{tabular}{|c|c|c|c|c|c|c|}
\hline \multirow[b]{2}{*}{ Trait } & \multicolumn{2}{|c|}{$\begin{array}{l}\text { UW population } \\
\text { (PTA) }\end{array}$} & \multicolumn{2}{|c|}{$\begin{array}{c}\text { Israeli } \\
\text { population (EBV) }\end{array}$} & \multicolumn{2}{|c|}{$\begin{array}{l}\text { CDDR population } \\
\text { (PTA) }\end{array}$} \\
\hline & Mean & SD & Mean & SD & Mean & SD \\
\hline Fat, kg & -5.48 & 21.00 & 6.42 & 6.68 & 3.23 & 23.49 \\
\hline Fat percentage & -0.0002 & 0.008 & 0.036 & 0.067 & -0.002 & 0.009 \\
\hline Milk, kg & -142.69 & 540.56 & 79.65 & 170.65 & 110.71 & 741.26 \\
\hline Protein, $\mathrm{kg}$ & -6.43 & 14.53 & 4.87 & 4.12 & 7.11 & 21.38 \\
\hline Protein percentage & -0.008 & 0.003 & 0.023 & 0.038 & 0.001 & 0.004 \\
\hline Productive life & 0.59 & 1.07 & $\mathrm{NA}^{1}$ & NA & -2.24 & 13.11 \\
\hline SCS & 2.97 & 0.12 & -0.11 & 0.13 & 3.02 & 0.16 \\
\hline
\end{tabular}

${ }^{1} \mathrm{NA}=$ not available.

$$
y_{i j k l}=\mu+s_{i}+m g s_{j}+d_{i j k} \tau+f_{l}+\varepsilon_{i j k l}
$$

where $y_{i j k l}$ represents the PTA or YD for milk protein ( $\mathrm{kg}$ and \%), fat ( $\mathrm{kg}$ and \%), and PL of daughter $k$ of sire $i$ of maternal grandsire $j ; m g s_{j}$ represents the random effect for the maternal grand sire $j ; \tau$ represents an effect associated with Mycobacterium paratuberculosis infection status; $d_{i j k}$ is an indicator variable assuming values 0 or 1 for noninfected and infected cows, respectively. Mycobacterium paratuberculosis infection status was included in the model because the UW population was originally created to search for genetic markers associated with susceptibility to paratuberculosis; $f_{l}$ represents the effect of the $F G F 2$ gene $(1=\mathrm{AA}, \mathrm{AG}$, GG); and the remaining terms were as defined in the previous model. Although deviations for yield traits are corrected for the effect of contemporaries, individual measures of PL do not account for these differences; therefore, for this trait an additional random effect for herd was fitted in the analysis.

Additive genetic effect for the FGF2 locus on the individual records analysis was estimated as half of the difference between homozygotes: $\left(\hat{f}_{G G}-\hat{f}_{A A}\right) / 2$. Dominance effect was estimated as the difference between the heterozygote and the average of the 2 homozygotes. Complete dominance genetic effect was estimated as

Table 2. Primer sequences, locations, and product sizes

\begin{tabular}{llc}
\hline Primer (location) & Sequence & $\begin{array}{c}\text { Fragment } \\
\text { size (bp) }\end{array}$ \\
\hline FGF2-1 (5' UTR ${ }^{1}$ ) & GAAAGCTCCGCAATGTAGAG & 1,076 \\
FGF2-2 (intron 1) & CCAACAAGGACCTTTTAGTTGG & 626 \\
FGF2-3 (intron 1) & GTTAACAAGGCCAAGTGGAGG & \\
FGF2-4 (intron 2) & CTGCCTCACACGAGCTGTC & 502 \\
FGF2-5 (intron 2) & CTGCTCTTCCAAGGAGATGTG & 749 \\
FGF2-6 (3' UTR) & CCAAACTGAGCAGCTCACTG & \\
FGF2-7 (3' UTR) & CAGTGAGCTGCTCAGTTTGG & 476 \\
FGF2-8 (3' UTR) & CAGATCCCTCCTGAGTATTC & \\
FGF2-In1 (intron 1) & TCAGTCTTCACATCCGTCTCAG & 332 \\
FGF2-In2 (intron 1) & TCATACACTGAAGCCTGAAGC \\
FGF2-In3 (intron 1) & GAACCAGTCTGTTGTTCCGTGT & 490 \\
FGF2-In4 (intron 1) & CAGATCAGATCAGATCAGTCGCT & 320 \\
FGF2-In5 (intron 1) & GCATCAGGTTTGAGGATCAA & \\
FGF2-In6 (intron 1) & AGGATCAAGTTTCCACCTG & 530 \\
FGF2-In7 (intron 1) & TCACTCATGCCTGGAAGGGT & \\
FGF2-In8 (intron 1) & TATGTCCAGGTTGGCCTATAC & 390 \\
FGF2-In9 (intron 1) & AGAGTCTTTCTCTGAGTCAG & 472 \\
FGF2-In10 (intron 1) & TGAAGTCATTTGGTGAAGGC & \\
FGF2-In11 (intron 1) & CAGCAACTTAGCACTAGCTAC & \\
FGF2-In12 (intron 1) & CAGAGGCTCATTACATGGCC & \\
FGF2-In13 (intron 1) & ATGGTCCAGCTCTCACATCC & \\
FGF2-In14 (intron 1) & GTGTAATATGTCTGAAACATC & 460 \\
FGF2-In15 (intron 1) & GCTGATACTGGTACATTACT & \\
FGF2-In16 (intron 1) & GCAAACAGTGGCTACCTTGG & \\
FGF2-In17 (intron 2) & CCTGGTGGCTCAGATGGT & \\
FGF2-In18 (intron 2) & CTCAGAATTCTCATGCACT & \\
\hline
\end{tabular}

\footnotetext{
${ }^{1} \mathrm{UTR}=$ untranslated region.
} 
Table 3. Least squares means (LSM) for fibroblast growth factor 2 (FGF2) genotypes (AA, AG, and GG) and estimates of additive, dominance, and complete dominance effects for milk yield and composition traits and for productive life estimated from PTA in the University of Wisconsin population

\begin{tabular}{|c|c|c|c|c|c|c|}
\hline Trait & $\begin{array}{c}\text { LSM } \\
\text { AA }\end{array}$ & $\begin{array}{l}\text { LSM } \\
\text { AG }\end{array}$ & $\begin{array}{l}\text { LSM } \\
\text { GG }\end{array}$ & $\begin{array}{l}\text { Additive } \\
\text { effect }\end{array}$ & $\begin{array}{l}\text { Dominance } \\
\text { effect }\end{array}$ & $\begin{array}{l}\text { Complete } \\
\text { dominance }\end{array}$ \\
\hline at $\mathrm{r}-\mathrm{cos}$ & -7.46 & -2.91 & -4.49 & $1.48 \pm 1.12$ & $3.06 \pm 1.43^{*}$ & $2.27 \pm 1.06^{*}$ \\
\hline $\mathrm{Fa}$ & -1 & 0.71 & 0.4 & $4 \pm 0$ & $1.07 \pm 0$. & 0.95 \\
\hline Mil & 108.71 & 122.25 & 150.26 & $-20.77 \pm 29.57$ & $7.23 \pm 37.60$ & $-6.77 \pm 27.97$ \\
\hline Protein yield & -5.88 & -5.36 & -6.57 & $-0.34 \pm 0.79$ & $0.85 \pm 1.00$ & $0.25 \pm 0.74$ \\
\hline Protein percentage & -0.93 & -0.60 & -0.75 & $0.09 \pm 0.19$ & $0.24 \pm 0.24$ & $0.16 \pm 0.18$ \\
\hline Productive life & 0.34 & 0.49 & 0.49 & $0.07 \pm 0.03 \dagger$ & $0.08 \pm 0.05$ & $0.07 \pm 0.03^{*}$ \\
\hline
\end{tabular}

$\dagger P<0.1 ; * P<0.05$.

half of the difference between the heterozygote and recessive homozygote group: $\left(\hat{f}_{A G}-\hat{f}_{A A}\right) / 2$.

For the Israeli population, individual cow EBV for yield traits were analyzed using the mixed model used in the UW population with the exception of the $M$. paratuberculosis infectious status effect. All the analyses were implemented using the NLME library in R software v. 2.5.1 (http://www.r-project.org).

\section{RESULTS}

Using the DNA sequencing approach, only $1 \mathrm{~A} / \mathrm{G}$ SNP was detected, at position 11646 in intron 1 of $F G F 2$. The frequencies of alleles $\mathrm{A}$ and $\mathrm{G}$ in the UW resource population were 0.35 and 0.65 , respectively and the genotype frequencies $(\mathrm{AA}=0.13, \mathrm{AG}=0.45, \mathrm{GG}=0.42)$ were as expected for Hardy-Weinberg equilibrium. The frequencies of allele $\mathrm{G}$ in the CDDR and the Israeli populations were 0.63 and 0.55 , respectively. The association between the FGF2 SNP and milk production and health traits was examined in 851 cows from the UW population, in 1,316 bulls from the CDDR population, and in 606 cows from the Israeli Holstein population.

Table 3 shows the estimates of the additive, dominance, and complete dominance for PTA of milk production and PL traits in the UW population. Complete dominant gene action was significant for fat yield, fat percentage, and PL. A dominance genetic effect was significant for fat yield and fat percentage. For YD, complete dominant gene action was significant for fat yield $(P<0.05)$ and $\mathrm{PL}(P<0.01)$ with estimates of 9.27 $\pm 3.77 \mathrm{~kg}$ and $1.54 \pm 0.56$ mo respectively. An additive genetic effect was significant only for $\mathrm{PL}(\mathrm{P}<0.05)$, with an estimate of $1.22 \pm 0.57$ mo. For fat yield, the least-squares estimate of the AA genotype was 13.83 compared with 31.96 and $26.14 \mathrm{~kg}$ for the AG and GG genotypes, respectively. Similarly, for PL, the AG and GG genotypes showed an increase of 3.1 and $2.46 \mathrm{mo}$, respectively, compared with the AA genotype.
Table 4 shows the least squares mean estimates from milk production and SCS traits and gene action effects in the Israeli population. Analyses of genotypic effects revealed that the GG and AG genotypes were associated with a significant decrease in SCS and a significant increase in fat percentage compared with the AA genotype. Complete dominance effects were significant for both SCS and fat percentage. Although the analysis of genotypic effects did not reach the significance level for fat yield, the directions of the effects were consistent with those observed in the UW resource population. The least-squares mean estimates of the AA genotype for fat yield were lower than those of AG and GG genotypes (Table 4). There were no available data for productive life in the Israeli population.

For the CDDR population, analysis of PTA for milk yield and composition and PL did not reveal significant associations with any of the examined traits (Table 5). However, the directions of least squares estimates for fat yield were consistent with those in the UW population. The estimate of genotype AA was 5.59 vs. $6.77 \mathrm{~kg}$ of fat for genotype GG.

\section{DISCUSSION}

In this study, we aimed to investigate the IFNT and placental lactogen signal transduction pathway as a candidate pathway affecting production traits in dairy cattle. Our hypothesis is that candidate genes affecting quantitative traits can be identified by tracking their biological action through intracellular effector pathways. Given that FGF2 is a member of the IFNT signal transduction pathway and that it is expressed in the mammary gland, it was chosen for investigation of association with milk production and health traits. Using the pooled DNA sequencing approach to search for polymorphisms in 6,389 bp including $466 \mathrm{bp}$ of the 3 exons of the gene, only one SNP was identified: in intron 1 at position 11646. It is widely accepted that highly conserved sequences are less subject to mutations. For example, investigation of 481 segments that are abso- 
Table 4. Least squares means (LSM) for fibroblast growth factor 2 (FGF2) genotypes (AA, AG, and GG) and estimates of additive, dominance, and complete dominance effects for milk production and SCS traits estimated from EBV in the Israeli population

\begin{tabular}{lcccccr}
\hline Trait & $\begin{array}{c}\text { LSM } \\
\text { AA }\end{array}$ & $\begin{array}{c}\text { LSM } \\
\text { AG }\end{array}$ & $\begin{array}{c}\text { LSM } \\
\text { GG }\end{array}$ & $\begin{array}{c}\text { Additive } \\
\text { effect }\end{array}$ & $\begin{array}{c}\text { Dominance } \\
\text { effect }\end{array}$ & $\begin{array}{c}\text { Complete } \\
\text { dominance }\end{array}$ \\
\hline Fat yield & 5.26 & 6.85 & 5.95 & $0.34 \pm 0.34$ & $1.24 \pm 0.68 \dagger$ & $0.79 \pm 0.49 \dagger$ \\
Fat percentage & 0.019 & 0.038 & 0.035 & $0.007 \pm 0.005$ & $0.01 \pm 0.005 \dagger$ & $0.01 \pm 0.004^{*}$ \\
Milk yield & 99.36 & 83.77 & 69.56 & $-14.9 \pm 12.6$ & $-0.72 \pm 14.45$ & $-7.81 \pm 10.44$ \\
Protein yield & 4.95 & 5.08 & 4.78 & $-0.08 \pm 0.30$ & $0.22 \pm 0.34$ & $0.06 \pm 0.25$ \\
Protein percentage & 0.020 & 0.024 & 0.025 & $0.003 \pm 0.002$ & $0.002 \pm 0.002$ & $0.002 \pm 0.001$ \\
SCS & -0.066 & -0.110 & -0.117 & $-0.02 \pm 0.005^{* *}$ & $-0.02 \pm 0.01 \dagger$ & $-0.02 \pm 0.007^{* *}$ \\
\hline
\end{tabular}

$\dagger P<0.1 ; * P<0.05 ; * * P<0.01$.

lutely conserved between orthologous regions of the human, rat, and mouse genomes revealed almost no natural variation in the human population, and only 6 variants were found in a total of 106,767 bases examined (Bejerano et al., 2004). Indeed, use of the multiple sequence alignment program ClustalW (http://www.ebi.ac.uk/clustalw) revealed similarity of $97 \%$ among bovine, mouse, and human for the protein sequence of FGF2.

The SNP in FGF2 was investigated for association with production traits in 3 Holstein populations: the granddaughter-design CDDR and the daughter-design UW populations from the United States and a daughter-design population from Israel. Significant associations between $F G F 2$ variants and fat yield and percentage, SCS, and PL traits were observed in the UW and the Israeli populations but not in the CDDR population. For the Israeli population, a significant decrease in SCS was found to be associated with the GG genotype of FGF2 with complete dominance of the G allele. Productive life data were not available for this population. However, the correlation between SCS and PL in the North American Holstein population is -0.36 (Khatib et al., 2005). Both SCS and PL are indicators of health conditions in cows. Productive life is a longevity trait defined as a cow's total lifetime months in milk with limits of 10 mo per lactation and $7 \mathrm{yr}$ of age (VanRaden and Wiggans, 1995). The GG genotype was associated with an increase in fat traits in the Israeli population with dominance and complete dominance effects similar to those found in the UW resource population. Thus, association of FGF2 with milk composition and health traits was consistent in the examined populations.

In a previous study, we reported a significant association between the protease inhibitor gene (PI) and PL and milk composition traits in Holstein dairy cattle (Khatib et al., 2005). In a subsequent study aimed at investigating the $P I$ region, we reported the association of the UTMP gene (located on bovine chromosome 21 within $321.6 \mathrm{~kb}$ of $P I$ ) with PL in both the CDDR and the UW populations (Khatib et al., 2007a). We concluded that additional studies are needed to confirm whether the observed associations between PI and UTMP with PL were due to polymorphisms in these genes or to other loci in that region. In this study, we found that FGF2, which is a member of the same pathway as UTMP, was also associated with a significant increase in PL.

This is the first report of the association between FGF2 and production traits in dairy cattle. However, it remains to be investigated by which mechanisms FGF2 affects these traits. For milk composition traits, it has been reported that $F G F 2$ is expressed in the mammary gland and plays a role in local regulation of mammary development in mouse (Coleman-Krnacik and Rosen, 1994) and in cattle (Plath et al., 1998). In addition, FGF2 has been reported to stimulate IFNT expression (Michael et al., 2006), which in turn acti-

Table 5. Least squares means (LSM) for fibroblast growth factor 2 (FGF2) genotypes (AA, AG, and GG) and estimates of additive, dominance, and complete dominance effects for milk yield and composition traits and for productive life estimated from PTA in the Cooperative Dairy DNA Repository population

\begin{tabular}{lcccccc}
\hline Trait & $\begin{array}{c}\text { LSM } \\
\text { AA }\end{array}$ & $\begin{array}{c}\text { LSM } \\
\text { AG }\end{array}$ & $\begin{array}{c}\text { LSM } \\
\text { GG }\end{array}$ & $\begin{array}{c}\text { Additive } \\
\text { effect }\end{array}$ & $\begin{array}{c}\text { Dominance } \\
\text { effect }\end{array}$ & $\begin{array}{c}\text { Complete } \\
\text { dominance }\end{array}$ \\
\hline Fat yield & 5.59 & 5.33 & 6.77 & $0.59 \pm 0.98$ & $-0.85 \pm 1.18$ & $-0.13 \pm 0.87$ \\
Fat percentage & -0.010 & 0.009 & -0.030 & $0.050 \pm 0.040$ & $-0.001 \pm 0.040$ & $0.020 \pm 0.030$ \\
Milk yield & 268.24 & 223.60 & 220.52 & $-23.85 \pm 25.50$ & $-20.77 \pm 31.95$ & $-22.31 \pm 23.48$ \\
Protein yield & 11.97 & 11.19 & 11.43 & $-0.26 \pm 0.67$ & $-0.50 \pm 0.81$ & $-0.38 \pm 0.60$ \\
Protein percentage & 0.015 & 0.017 & 0.019 & $0.018 \pm 0.010$ & $0.003 \pm 0.020$ & $0.010 \pm 0.010$ \\
Productive life & -0.4 & -0.38 & -0.42 & $0.19 \pm 0.55$ & $0.59 \pm 0.37$ & $0.39 \pm 0.49$ \\
\hline
\end{tabular}


vates a cascade of genes previously found to be associated with milk production and health traits.

Bovine IFNT is released by the conceptus as early as d 9 of pregnancy and serves as the signal for maternal recognition of pregnancy. Interferon- $\tau$ binds to the receptor IFNAR present on the cells of the endometrium and activates the phosphorylation of janus kinases JAK1 and TYK2, which in turn phosphorylate the tyrosine residues of STAT1 and STAT2. Following phosphorylation, both STAT1 and STAT2 are released from the receptor and bind a third DNA-binding protein, interferon regulatory factor (IRF) 9, to form the ISGF3 complex. Then, the ISGF3 complex translocates from the cytoplasm to the nucleus and binds to the promoter region of $I R F 1$ to increase the rate of transcription of targeted genes such as STAT1, STAT2, IRF9, and 2', $5^{\prime}$ oligoadenylate synthetase $(O A S)$. Expression of OAS may enhance the secretion of UTMP and OPN proteins (Spencer and Bazer, 2002; Stewart et al., 2002). The expression of UTMP is also induced by STAT5, which is stimulated by the growth hormone receptor (Spencer and Bazer, 2002, 2004; Stewart et al., 2002). Several members of this pathway, including STAT1 (Cobanoglu et al., 2006), UTMP (Khatib et al., 2007a), OPN (Leonard et al., 2005), STAT5 (Khatib et al., 2008), and growth hormone receptor (Blott et al., 2003) have been reported to be associated with milk production and health traits. Taken together, our findings support the usefulness of the candidate pathway strategy in choosing candidate genes affecting quantitative traits.

\section{ACKNOWLEDGMENTS}

This research was supported by Babcock Institute for International Dairy Research and Development, University of Wisconsin-Madison and by The Draper Technology Innovation Fund from Graduate School, the University of Wisconsin-Madison. We thank George E. Shook for providing blood samples from the UW Resource population. We thank the USDA Bovine Functional Genomics Laboratory staff for providing semen samples from the CDDR population.

\section{REFERENCES}

Bejerano, G., M. Pheasant, I. Makunin, S. Stephen, W. J. Kent, J. S. Mattick, and D. Haussler. 2004. Ultraconserved elements in the human genome. Science 304:1321-1325.

Blott, S., J. J. Kim, S. Moisio, A. Schmidt-Küntzel, A. Cornet, P. Berzi, N. Cambisano, C. Ford, G. Grisart, D. Johnson, L. Karim, P. Simon, R. Snell, R. Spelman, J. Wong, J. Vilkki, M. Georges, F. Farnir, and W. Coppieters. 2003. Molecular dissection of a quantitative trait locus: A phenylalanine-to-tyrosine substitution in the transmembrane domain of the bovine growth hormone receptor is associated with a major effect on milk yield and composition. Genetics 163:253-266.

Cobanoglu, O., I. Zaitoun, Y. M. Chang, G. E. Shook, and H. Khatib. 2006. Effects of the signal transducer and activator of transcription 1 (STAT1) gene on milk production traits in Holstein dairy cattle. J. Dairy Sci. 89:4433-4437.

Coleman-Krnacik, S., and J. M. Rosen. 1994. Differential temporal and spatial gene expression of fibroblast growth factor family members during mouse mammary gland development. Mol. Endocrinol. 8:218-229.

Gonda, M. G., Y. M. Chang, G. E. Shook, M. T. Collins, and B. W. Kirkpatrick. 2006. Genetic variation of Mycobacterium avium ssp. paratuberculosis infection in US Holsteins. J. Dairy Sci. 89:1804-1812.

Khatib, H., E. Heifetz, and J. C. Dekkers. 2005. Association of the protease inhibitor gene with production traits in Holstein dairy cattle. J. Dairy Sci. 88:1208-1213.

Khatib, H., R. L. Monson, V. Schutzkus, D. M. Kohl, G. J. M. Rosa, and J. J. Rutledge. 2008. Mutations in the STAT5A gene are associated with embryonic survival and milk composition in cattle. J. Dairy Sci. 91:784-793.

Khatib, H., V. Schutzkus, Y. M. Chang, and G. J. M. Rosa. 2007a. Pattern of expression of the uterine milk protein gene and its association with productive life in dairy cattle. J. Dairy Sci. 90:2427-2433.

Khatib, H., I. Zaitoun, J. Wiebelhaus-Finger, Y. M. Chang, and G. J. M. Rosa. 2007b. The association of bovine PPARGC1A and OPN genes with milk composition in two independent Holstein cattle populations. J. Dairy Sci. 90:2966-2970.

Khatkar, M. S., P. C. Thomson, I. Tammen, and H. W. Raadsma. 2004. Quantitative trait loci mapping in dairy cattle: Review and meta-analysis. Genet. Sel. Evol. 36:163-190.

Leonard, S., H. Khatib, V. Schutzkus, Y. M. Chang, and C. Maltecca. 2005. Effects of the osteopontin gene variants on milk production traits in dairy cattle. J. Dairy Sci. 88:4083-4086.

Michael, D. D., I. M. Alvarex, O. M. Ocón, A. M. Powell, N. C. Talbot, S. E. Johnson, and A. D. Ealy. 2006. Fibroblast growth factor-2 is expressed by the bovine uterus and stimulates interferon-tau production in bovine trophectoderm. Endocrinology 147:35713579 .

Ocón-Grove, O. M., F. N. Cooke, I. M. Alvarez, S. E. Johnson, T. L. Ott, and A. D. Ealy. 2008. Ovine endometrial expression of fibroblast growth factor (FGF) 2 and conceptus expression of FGF receptors during early pregnancy. Domest. Anim. Endocrinol. 34:135-145.

Plath, A., R. Einspanier, C. Gabler, F. Peters, F. Sinowatz, D. Gospodarowicz, and D. Schams. 1998. Expression and localization of members of the fibroblast growth factor family in the bovine mammary gland. J. Dairy Sci. 81:2604-2613.

Rothschild, M. F., and M. Soller. 1997. Candidate gene analysis to detect genes controlling traits of economic importance in domestic livestock. Probe 8:13-22.

Spencer, T. E., and F. W. Bazer. 2002. Biology of progesterone action during pregnancy recognition and maintenance of pregnancy. Front. Biosci. 1:d1879-d1898.

Spencer, T. E., and F. W. Bazer. 2004. Conceptus signals for establishment and maintenance of pregnancy. Reprod. Biol. Endocrinol. 2:49.

Stewart, M. D., Y. Choi, G. A. Johnson, L. Y. Yu-Lee, F. W. Bazer, and T. E. Spencer. 2002. Roles of Stat1, Stat2, and interferon regulatory factor-9 (IRF-9) in interferon tau regulation of IRF-1. Biol. Reprod. 66:393-400.

VanRaden, P. M., and G. R. Wiggans. 1995. Productive life evaluations: Calculation, accuracy, and economic value. J. Dairy Sci. 78:631-638 